1 Universidade Estadual do Ceará (UFCE) - Fortaleza (CE), Brasil.

anayamayana@gmail.com

\section{'Uma semente abrindo a terra para germinar': o processo formativo com educadores/as populares do EdPopSUS}

\author{
'A seed opening the ground to germinate': the training process with \\ EdPopSUS popular educators
}

Mayana de Azevedo Dantas $\mathbf{1}$, Maria Rocineide Ferreira da Silva', André Ribeiro de Castro Júnior ${ }^{\mathbf{1}}$, Lúcia Conde de Oliveira'

DOI: 10.1590/0103-1104202012503

RESUMO A educação popular em saúde é uma estratégia de fortalecimento da participação popular na rearticulação da Reforma Sanitária Brasileira. Como efetivação da Política Nacional de Educação Popular em Saúde, tem-se o Curso Livre de Educação Popular em Saúde (EdPopSUS). Os educadores do EdPopSUS passam por uma seleção pública composta de um curso de 40 horas. A coordenação do Ceará realizou, autonomamente, processo de educação permanente após a etapa seletiva. Este artigo objetivou constituir um olhar sobre a formação inicial e sobre a educação permanente vivenciadas pelos/as educadores/as, analisando os conflitos desses processos à luz da educação popular, em diálogo com as superações produzidas a partir de atos-limites. Nesta pesquisa de abordagem qualitativa, baseada no estudo de caso, realizou-se análise de conteúdo de um corpus constituído por 23 entrevistas. Foram evidenciadas quatro categorias: processo inicial, princípios da educação popular, situações-limites e ação-reflexão-ação. O curso possibilitou a concretização dos princípios da educação popular. A competição para a seleção, a não participação em todos os momentos e a constituição das duplas foram algumas das situações-limites experienciadas pelos/as educadores/as. Tais situações foram mediadas pela vivência dos princípios da educação popular, apontando atos-limites para o seu exercício na conjuntura atual, especialmente no âmbito do Sistema Único de Saúde.

PALAVRAS-CHAVE Educação popular. Educação em saúde. Educação permanente. Promoção à saúde. Sistema Único de Saúde.

ABSTRACT Popular education in health is a strategy to strengthen popular participation in the rearticulation of the Brazilian Sanitary Reform. As a result of the National Policy for Popular Education in Health, there is the Free Course of Popular Education in Health (EdPopSUS). EdPopSUS educators go through a public selection made up of a 40-hour course. The coordination of Ceará carried out, independently, a permanent education process after the selective stage. This article aimed to constitute a look at the initial formation and permanent education experienced by the educators, analyzing the conflicts of these processes in the light of popular education, in dialogue with the overcoming produced from limiting-acts. In this qualitative research, based on the case study, content analysis of a corpus consisting of 23 interviews was carried out. Four categories were highlighted: initial process, principles of popular education, limit-situations and action-reflection-action. The course made it possible to implement the principles of popular education. The competition for selection, the non-participation at all times and the formation of pairs were some of the limit situations experienced by educators. Such situations were mediated by the experience of the principles of popular education, pointing out limiting-acts for its exercise in the current situation, especially within the scope of the Unified Health System.

KEYWORDS Popular education. Education in health. Permanent education. Health promotion. Unified Health System. 


\section{Introdução}

A educação popular em saúde põe-se como estratégia de fortalecimento da participação popular na rearticulação do segmento social, o mais fragilizado na Reforma Sanitária Brasileira (RSB) ${ }^{1}$. A Política Nacional de Educação Popular em Saúde no âmbito do Sistema Único de Saúde (PNEP-SUS) foi aprovada em 2013, como resultado de lutas envolvendo os movimentos sociais e populares desse âmbito, que têm uma história de mais de meio século². Ela traz como principal estratégia de efetivação o Curso Livre de Educação Popular em Saúde (EdPopSUS), o qual já teve duas edições: um curso técnico e, mais recentemente, um aperfeiçoamento. Nesta edição, o EdPopSUS incluiu, como público, além dos Agentes Comunitários de Saúde (ACS) e dos Agentes de Combate às Endemias (ACE), outros trabalhadores do SUS e membros de movimentos sociais. Constituído de encontros presenciais e trabalhos de campo, tem carga horária de 160 horas, distribuídas em 17 encontros. O Ceará recebeu turmas em ambas as edições, tendo realizado duas chamadas; nesta última, envolveu 12 municípios.

Os/As educadores/as que conduziram tal processo nos territórios passaram por uma seleção pública composta por quatro fases, sendo o curso de educação popular em saúde a última delas. Essa formação teve 40 horas/ aula, durando uma semana. A equipe de coordenação do Ceará realizou, autonomamente, a continuidade da formação após a seleção, durante os encontros com os/as educandos/ as nos municípios.

Destarte, este artigo objetiva constituir um olhar sobre os processos da formação inicial e de educação permanente vivenciados pelos/ as educadores/as, analisando os conflitos desses processos à luz da educação popular, em diálogo com as superações produzidas a partir de atos-limites. Foram evidenciadas quatro categorias: processo inicial de 40 horas, princípios da educação popular, situações-limites e ação-reflexão-ação.
$\mathrm{O}$ artigo intencionou responder às questões: que estratégias foram concretizadas no curso para a efetivação do compromisso dos/as educadores/as com este e com seus territórios de atuação? A formação propiciou aprendizagens entre os/as educadores/as de forma crítica e transformadora? Quais as situações-limites vivenciadas no processo? Foi possível para os/ as educadores/as vivenciarem atos-limites?

\section{Material e métodos}

Nesta pesquisa de abordagem qualitativa, baseada no estudo de caso, realizou-se análise de conteúdo de um corpus constituído por 23 entrevistas. Compreendendo a relação mundo-sujeito de forma ativa e inseparável, não passível de tradução em números, a abordagem qualitativa coloca o pesquisador como instrumento-chave; e o ambiente natural, como fonte dos dados ${ }^{3}$. Já o estudo de caso configura-se uma investigação de acontecimentos do tempo presente em seu contexto real, compondo-se por generalizações a conjecturas teóricas, e não a populações e universos ${ }^{4}$.

A investigação deu-se nos cenários de prática da formação dos/as educadores/as-educandos/ as da segunda chamada de turmas do EdPopSUS no Ceará, que se realizou entre 2017 e 2018 e envolveu 12 municípios nesse estado. Esta pesquisa, por sua vez, efetivou-se de dezembro de 2017 a janeiro de 2019. As entrevistas em profundidade, compostas de 9 questões norteadoras, formaram o meio de coletar dados. Entre os/as 23 educadores/as envolvidos/as, 5 já eram selecionados/as da turma anterior. Haviam participado da edição anterior 10 educadores/as, e 13 já eram atuantes em movimentos sociais. Ademais, 17 educadores eram do sexo masculino; e 5 , do feminino.

Realizou-se a análise temática dos dados que consiste em descobrir os núcleos de sentido de determinada comunicação, compondo-se de três etapas: pré-análise, exploração do material e tratamento dos resultados obtidos/interpretação ${ }^{5}$. Para a primeira etapa, 
constituiu-se um corpus textual a partir das 23 entrevistas transcritas. Com vistas à resposta das normas de exaustividade, representatividade, homogeneidade, objetividade e pertinência ${ }^{6}$, obteve-se auxílio por meio do programa IRaMuTeQ (Interface de R pour les Analyses Multidimensionnelles de Textes et de Questionnaires), versão 0.7 Alpha 2. Além da sua liberdade de uso, essa escolha deu-se pela desenvoltura na codificação, organização e separação dos dados, encontrando com rapidez todo o segmento de texto ${ }^{7}$. A utilização do IRaMuTeQ auxilia com a divisão do corpus em classes temáticas conforme a similitude das palavras evocadas pelos sujeitos produtores daquele corpus. Entre as possibilidades do programa, optou-se pela Classificação Hierárquica Descendente (CHD) que dividiu o corpus em quatro classes. A partir delas, visou-se à reformulação das premissas, à definição das unidades de registro e de contexto, dos recortes, da forma de categorizar, da modalidade de codificação e dos conceitos teóricos de orientação ${ }^{5}$.
A categorização dos dados deu-se na etapa de exploração do material quando se retornou ao corpus textual para definição das regras de contagem. Para tanto, observaram-se as falas destacando as palavras mais significativas em colorido de acordo com as classes geradas pela CHD. Assim, procuraram-se expressões relevantes em função das quais se organizou o conteúdo da fala, alocando-as, visualizando e analisando seu contexto original com falas semelhantes. A classificação e a agregação dos dados potencializaram as categorias teóricas, engravidando-as com os sentidos e originando as categorias empíricas, resultando em temas e subtemas.

$\mathrm{Na}$ terceira etapa - Tratamento dos Resultados Obtidos e Interpretação -, inter-relacionou-se o quadro teórico inicial aos dados, redimensionando-os de acordo com as indicações da leitura do material ${ }^{4}$. Finalmente, construíram-se quatro temas: chão(-universo) da educação popular, processo formativo, condução em dupla e aprendizagens com o corpo todo. A formação dos temas pode ser visualizada na imagem a seguir:

Figura 1. Temas surgidos na pesquisa

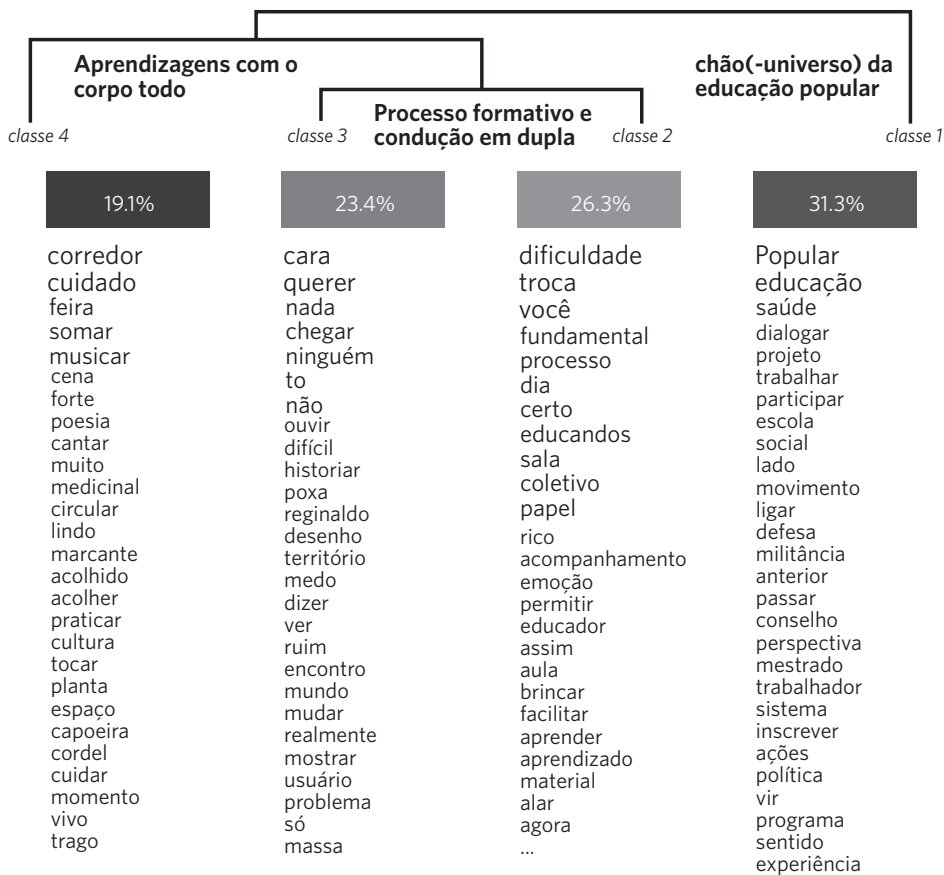

Fonte: Elaboração própria a partir de imagem gerada pelo IRaMuTeQ. 
Neste estudo, ateve-se ao tema Processo formativo, relativo à formação inicial e de continuidade dos/as educadores/as. Nele, são aprofundados os princípios da educação popular, bem como as situações-limites do curso inicial e do processo de continuidade, além dos atos-limites efetivados nesse percurso. Tais pontos permitem uma análise sobre a relação entre os princípios da educação popular, as situações-limites e atos-limites vivenciados nesse processo. Ressalta-se que este estudo integra uma pesquisa de mestrado, aprovada pelo Comitê de Ética em Pesquisa da Universidade Estadual do Ceará, com o parecer de número 2.670.023.

\section{Resultados e discussão}

\section{Processo inicial de 40h: 'Uma experiência de liberdade coletiva'}

O percurso formativo inicial de 40 horas foi vivenciado, segundo alguns/as educadores/ as, como um momento de quase imersão. Despertou intensidades, inquietações, rupturas, produção de novas subjetividades e desterritorializações ${ }^{\mathbf{8}}$. Tais aprendizagens diversas foram possíveis por meio da criação de um campo fértil que propiciou um (re)encontro com o/a educador/a que os/as habitava.

Édesconcertante! Você vem dessa situação confortável, entra no processo, se embaralha. Coloca tudo em xeque, tem que encontrar um novo equilíbrio, novas lógicas, horizontes sobre como atuar como o educador que achava que era ou que quer vir a ser. (E13).

A preparação desse terreno propiciou a saída das caixas padronizadoras hegemônicas, que cristalizam o/a educador/a no professor/ $a^{9}$. Há um salto entre o ser professor/a e o ser educador/a. O/A professor/a é um(a) profissional, visto apenas em suas funções, descartável aos olhos do mercado. Já o/a educador/a nasce de uma vocação constituída de amor e exercida por uma pessoa ${ }^{10}$.

Me permitiu questionar minha prática, a maneira
que eu estava olhando para a realidade, as relações.
Nunca me reconheci esse educador que olha para
as diversas coisas que acontece na vida daquele
educando. Eu era muito professor. Como é que
pode? Se eu me coloco para construir algo diferente,
como estou reproduzindo as mesmas coisas? (E9).

Nesse embaralhamento de aspectos pessoais e profissionais, os aprendizados são evidenciados nas falas: "Aprendi a ouvir mais" (E21), "Como se fosse uma borboleta no casulo, fui me abrindo pra essas novas experiências" (E7). Estes apontam para a desconstrução dos sujeitos e educadores/as que vinham sendo até então. Incluíram-se suas subjetividades, limitações, histórias, percepções, ideologias e utopias.

\section{Mergulhar no traçado pedagógico e metodológico do curso, trabalhar dialogicidade, amorosidade, problematização. Começaram a produzir inquie- tação, reflexão [...]. Teve essa preocupação. Como vamos chegar lá no município? Repassar toda essa avalanche de conhecimentos partilhados aqui? (E2).}

A fala acima revela que a potencialidade do vivido também pode gerar medo. Porém, este medo vem acompanhado da ideia de reprodução. Como outro/a educador/a ressaltou, a transformação é um processo, e os resquícios da educação bancária ainda permeiam o ideário que constitui esses sujeitos. Na educação bancária, compete ao/à educador/a persuadir o/a educando/a e substituir o conhecimento trazido por ele/a em troca daquele trazido pelo/a educador/an'; o que poderia ser identificado com o uso do verbo 'repassar'. $\mathrm{O}$ simples repasse de informações não estimula a curiosidade epistemológica que ativa o espírito investigador e criativo dos/as educandos/as ${ }^{\mathbf{1 2}}$. Tal estímulo teria sido vivenciado na formação, segundo a expressão 'conhecimentos partilhados aqui'. 
Quando me encontrei com aquelas pessoas novamente foi como se eu pudesse respirar de novo o ar de se estar na educação de forma livre. É uma grande experiência de liberdade coletiva, um exercício do nosso jeito de ser. Momento de reencontro e de conhecer pessoas que estavam chegando [...], os que já tinham participado, não que não devessem estar [...], mas também eram educadores-educando em certa medida. (E18).

Encontros, desafios e reencontros possibilitaram a superação de situações-limites na relação com os/as outros/as educadores/as, o reconhecimento e a inclusão de suas singularidades durante o processo formativo inicial. A consideração dos saberes acumulados daqueles/as que já haviam participado da turma anterior desta edição do EdPopSUS permitiu que estes/as educadores/as contribuíssem como animadores/as do processo com os/as coordenadores/as e participassem também como educandos/as.

Naquela primeira oficina [da chamada anterior quando também estava sendo selecionado], percebi que pessoas competiam diretamente comigo. No segundo encontro, consegui me tocar que o participar efetivamente te colocava numa boa posição para a competição [...]. Ser educador popular num mundo capitalista e na sociedade em que a gente vive tem que ser, no mínimo, um sonhador, ter uma força motriz, fincar na realidade com uma percepção mais apurada. Nesta chamada em que a gente já tinha sido selecionado, outras pessoas estavam competindo entre si. Nesse patamar, eu pude conversar com quem estava fragilizado por esta questão. Tentei tranquilizar [...]. (E10).

A situação diferenciada entre os/as educadores/as que participavam ou não de uma seleção apontou a solidariedade como ato-limite. $\mathrm{O}$ desafio posto pela formação pode estar refletindo o contexto desfavorável à atuação do/a educador/a popular na atualidade que segue negligenciado/a pelo sistema capitalista à medida que exclui a perspectiva crítica da educação. Não obstante, o reencontro com esse lugar institucional da educação popular em saúde provoca um olhar aprofundado sobre outros possíveis caminhos a serem percorridos pelo/a educador/a.

Foi um redespertar! Quando você se reencontra, se percebe potente, se descobre transformando e transformador, é como uma semente que vai abrindo a terra para germinar [...]. Venho de contato com os grupos, militante, de fazer coisas com liberdade, de ser artístico, de brincar, do aprendizado que aprende com o corpo todo, fazendo música, teatro em coletivo. Já estava vivendo um distanciamento disso. (E20).

O processo formativo inicial revelou-se, ainda, uma oportunidade de retorno às experiências com os movimentos que vinham sendo impossibilitadas pela dinâmica da sociedade capitalista. Esta requer professores/as geridos/ as pela excelência funcional ao invés de educadores/as para quem a interioridade, suas utopias, visões, paixões e esperanças fazem diferença ${ }^{10}$.

Alguns/as entre os/as educadores/as relacionavam-se como companheiros/as de luta. Estes/as, por vezes, encontravam-se distanciados/as. No entanto, o desejo de encontro com os/as outros/as alimentou o esperançar: "O estar junto já é um grande momento. A gente tinha aquela vontade de chegar lá na hora, ouvir as histórias de cada um" (E1). O esperançar é o estado natural do ser humano que ativa sua força motriz de resistência à desesperança imobilizadora que é permanentemente ativada por seu contexto ${ }^{13}$.

A potência do encontro resulta também dos afetos produzidos nele. "Rico mesmo éo encontro, como o Ray costuma dizer: 'quando a gente se encontra é bem mais que um encontro"' (E21). O encontro segue despertando o desejo de conhecer cada vez mais o Outro com quem se compõe um coletivo, residindo, nesse aspecto, a efetivação do compromisso com o curso. 


\section{'Mergulhar no traçado pedagógico': dos princípios da educação popular}

Como visto, a curiosidade e a amorosidade, princípios da educação popular, concretizaram-se, como aspectos vivenciados no processo formativo. Outros princípios da educação popular foram desvelados por um conjunto de falas ao referir-se à formação inicial de 40 horas. Como se necessitassem uns dos outros para serem ativados, estes mostraram-se em permanente interação.

A sensibilidade de cada um abriu espaços para o autoconhecimento, para o diálogo um com o outro, com as suas experiências no local, o respeito com o que o outro pensa. Quando a gente discutia o papel do EdPopSUS era permitir dialogar uma proposta, que nem diz aqui, conversar miolo de pote. No pote tem água e água é coisa rica, a gente torna a vida mais saudável, forte, passa a dar mais valor à vida. (E8).

A consciência do inacabamento possibilita o diálogo. Os sistemas de educação e de saúde hegemônicos impõem ao/à educador/a e ao/à trabalhador/a de saúde um saber pronto. Ambos, de maneiras distintas, asseguram suas práticas na conquista dos/as educandos/as e dos/as usuários/as por meio da imposição de seus saberes ${ }^{14,15}$. Na relação dialógica, por sua vez, reconhece-se o que não sabe, abrindo-se ao mundo e ao saber do outro ${ }^{13}$.

O ser humano, em movimento com o mundo e com o outro, politiza-se, pois reflete e transforma a ambos, a si e ao mundo ${ }^{12,16}$. Se o protagonismo e a autoria são pressupostos imprescindíveis à educação popular como política, faz-se necessário, nesse processo formativo, compreender as lutas e as conquistas que resultaram no SUS, resgatando historicamente a participação dos movimentos populares na construção da RSB ${ }^{17}$.

Trouxe reflexões importantes sobre humanização nos serviços, compreender, fortalecer, defender o SUS. Educação popular em saúde nasce nessa gênese fantástica desse sistema universal, equânime. Trazia as principais fissuras existentes nesse cenário de desmonte que nós estamos vivenciando hoje e nos desafiando em construir e a fazer educação popular em saúde dentro desse cenário. (E2).

O cenário referido pelo/a educador/a é o contexto sociopolítico-econômico brasileiro que, estimulado por forças conservadoras, visa à mercantilização dos direitos sociais, desmontando o SUS constitucional, prescindindo da Estratégia Saúde da Família (ESF) como modelo de Atenção Primária à Saúde (APS) e descaracterizando o trabalho do/a ACS ${ }^{18}$, principal público do curso que tais educadores/as facilitarão. Esse quadro reflete o aprofundamento do golpe parlamentar midiático com apoio do Judiciário em 2016, que concretizou um impeachment de uma presidente eleita sem fundamentação jurídica ${ }^{\mathbf{1 9} 20}$. Nesse contexto, vem sendo reforçado um Estado policial e retrocessos democráticos, impondo um ajuste fiscal para atender, prioritariamente, aos interesses do sistema financeiro e dos capitalistas, aprovando medidas que ferem a Constituição, e rompe com o Pacto Social celebrado em 1988, a exemplo da redução dos direitos trabalhistas, da terceirização de atividades-meio e fim e do congelamento de gastos públicos com saúde e educação por $20 \operatorname{anos}^{20}$. Tais retrocessos foram facilitados pelo distanciamento da RSB em relação à ênfase política e a movimentos estratégicos com vistas à apropriação por parte da maioria da população, o que efetivaria, além da conquista constitucional, a legitimação e integração social do SUS ${ }^{21}$.

Entretanto, é necessário retomar as iniciativas comunitárias e de movimentos sociais capazes de produzir saberes locais, apontando para uma dinâmica de vida que amplia a coesão da sociedade civil e favorece interesses $\operatorname{coletivos}^{22}$. Na região Nordeste, onde se deu o curso analisado, o peso das heranças culturais age fortemente como resistência aos modos de viver globalizantes ${ }^{23}$. A reflexão do/a educador/a realizada, no contexto do curso, acentua-se atualmente, ecoando sua 
voz: que fissuras foram encontradas, no cenário atual, para uma prática libertária na educação e na saúde?

A necessidade de transformação do mundo articula-se à incompletude humana ${ }^{13}$. Assim, cumpre-se a indispensável diversidade de saberes nos processos comunicacionais e pedagógicos:

Essa experiência humanizada do saber, todo mundo junto fazendo a troca, não havia essa história de que fulano sabia mais ou que sabia menos. Todo mundo sabia igual. (E14).

Proposta pela construção compartilhada do conhecimento, essa diversidade propicia uma compreensão mais efetiva na transformação coletiva das ações de saúde em suas dimensões políticas, teóricas e práticas ${ }^{23}$.

Achei que eu não tinha nada a ofertar, mas o que eu sei alguns não sabiam e aprenderam comigo. Coisas que eu não tinha noção e aprendi com o outro. Você está na formação com o compromisso de aprender. Que é que eu vou fazer com o que eu aprendi aqui? Eu vou praticar aonde? Tem que ter responsabilidade com o que está aprendendo. (E19).

Segundo os relatos, as bases do processo formativo constituíram-se da inclusão dos saberes-de-experiência-feito dos/as educandos/as-educadores/as, criando condições de superação da passividade usual nas relações educativas hegemônicas. O protagonismo permite a criatividade e a criticidade ${ }^{24}$, bastante temida pelas elites que buscam, esforçadamente, a transformação da mente das classes subalternas para manter a situação que as oprime ${ }^{25}$.

Foi um mergulho na proposta do curso. Ele tinha todo um processo trilhado, trajeto, percurso. Uma semana de vivenciar, na prática profissional, no cotidiano daquele sujeito, da experiência de vida que estavam trazendo, o que era mais importante, mais vivencial, prático. (E3).
O que se se produz compõe-se de uma parte do indivíduo, permitindo, por meio do protagonismo, o despertar do compromisso. A construção de sujeitos comprometidos com os saberes, os/as educandos/as e o processo é o que preza a educação popular. Tal atitude só pode advir da transição da consciência ingênua à crítica, pois é nesta que o homem se percebe parte da história ${ }^{26}$. Sendo assim, propõe-se à formação um norteamento por princípios vivos que se aplicam em todos os seus âmbitos.

Cheguei já armado. Queria mostrar que eu já sei, quando um passo em que permite você aprender mais é quando descobre que ainda não sabe. Fui me impressionando com o que eu estava apreendendo. [...]. Desenvolver uma sistemática de produção de conhecimento que permita orientar essas experiências para qual é a transformação que você quer fazer/ser no mundo. [...] Momento intenso de profusão de coisas, de dar uma dinamitada na gente e sair perguntando: o que é que eu vivenciei? (E13).

Entre os princípios apontados nas falas, o inacabamento do ser humano foi o mais frequente. As noções de educador $/ \mathrm{a}^{10} \mathrm{e}$ de professor/a crítico/a ${ }^{13}$ aproximam-se pelo caráter aventureiro de quem orienta a aprendizagem. Este/a desapega-se permanentemente dos saberes já construídos em nome de outros caminhos, que se apresentam mais pulsantes no momento. Saberes a serem construídos coletivamente, revelando o caráter nômade do/a educador/a popular.

Obtive alguns conhecimentos, pude compartilhar outros e uni, modifiquei o modelo tradicional de ensino com o de educação popular em saúde. Foi novo, eu não tinha essa experiência, mas fiquei com todo gás referente a aprender essas novas metodologias. (E16).

Pode-se identificar, por meio das falas, que o curso apresenta propostas que permitem a reflexão sobre o vivido, como a sistematização das experiências. Contudo, a intensificação do 
processo ensino-aprendizagem se dá por meio da complementariedade entre a vivência e o entendimento racional: "Como se passasse todo esse filme, pudesse revisar tudo que vivenciei e, sentindo bem forte, iniciar a formação com os educandos no território" (E23). Isso estaria se dando visto que, no coletivo, a efetivação dos laços afetivos comporia a base do processo, dando cabo à racionalização dos princípios em um momento posterior?

Você fica naquela necessidade de ter mais tempo para viver e degustar com mais sabor cada coisa, cada momento, porque, como é muito intenso, muitas vezes, a coisa passa e, no outro dia, você se dá conta do que viveu, do que era aquilo. (E20).

Os/As educandos/as-educadores/as respaldaram o papel daqueles/as que foram seus/ suas educadores/as durante esse percurso. Estes/as compunham um grupo formado substancialmente pela equipe de coordenação do curso, alguns/as apoiadores/as institucionais e informais, além de convidados/as:

Os educadores dos educadores, traziam muita experiência. Uma troca muito rica, a construção de referenciais, olhar sobre os caminhos que cada educador ia levar, construção de estratégias educativas [...]. (E6).

A forma de conduzir ganha notoriedade com a percepção de que tais educadores/as conseguiram trabalhar coletivamente uma proposta formativa em educação popular imersos/as na complexidade de realizar um processo seletivo: "Cada vez mais, eu venho percebendo que a condução, aqui, no Ceará, leva a não disputa. Esta é uma casa que me cabe" (E1). Isso se dá, segundo as falas, pelo acesso aos próprios princípios da educação popular por parte dos sujeitos do grupo. Uma atitude que rediz ao invés de desdizer, condiz com a rigorosidade do pensar certo ao corporificar as palavras no exemplo ${ }^{13}$. Ao pensar certo, diferentemente do pensar mecânico, o/a educador/a constitui-se um/a desafiador/a que busca, criticamente, afastar-se da arrogância de quem está certo demasiadamente de suas certezas, este, por sua vez, mostra-se um/a memorizador/a, repetindo palavras descontextualizadas da realidade ${ }^{13}$.

Nos momentos em que são mais difíceis ou que as pessoas ficam mais aperreadas, têm a costura da amorosidade, do diálogo, um olhar de quem está coordenando que te deixa mais seguro. [...] Tem uma coisa ríspida. É uma seleção! Mas tem toda a proposta trabalhada com princípios da educação popular. O discurso é próximo da prática das pessoas que estão conduzindo. (E10).

O modo de organização característico da educação popular configura o modo pelo qual a coordenação operacionaliza o curso, tendo um papel pedagógico crucial de exemplificar as possibilidades de efetivação nos territórios. Tal fato mostra-se ainda mais importante, visto que a educação popular é apontada como inviável ante os desafios dos modelos comunicacionais impostos ${ }^{11}$, o que reverbera nos campos de saúde e de educação em um contexto de intensas divergências com tal proposta.

\section{'A soma é que tem valor $e$, não, 0 saber individualizado': situações- limites de uma formação em disputa}

O ser humano é desafiado por situações-limites, dimensões concretas e históricas que se põem em seu contexto ${ }^{24}$. Nas falas dos/as educandos/as, situações-limites relativas ao aspecto seletivo da formação foram pontuadas consideravelmente. Tal caráter estaria exacerbando a competitividade própria do cotidiano capitalista. Uma contradição configurar-se-ia, já que a educação popular tem, como objetivo, transformar tal sociedade, sobretudo pela exclusão que lhe é característica.

Nos momentos que teve seleção, foi ruim [...]. Falando em educação popular, não dá para colocar disputa. Foi bem difícil, não gostei. Não estou aqui pra disputar com ninguém [...], a soma dos nossos saberes é que tem que ter valor e, não, o saber individualizado de ninguém. (E1). 
A falta de presença de todos/as os/as educadores/as na formação apresentou-se como outra situação-limite por meio de falas que ressaltaram a importância do coletivo, de que os sujeitos se conhecessem para corporificar o princípio da construção compartilhada do conhecimento. Essa preocupação ressalta que a presença precisa tornar-se convivência para, então, intervir no mundo ${ }^{13}$.

Houve dificuldades, porque a gente, que já tinha sido selecionado na primeira etapa, não participou de todos os momentos da oficina. Não tive a oportunidade, que foi importante na primeira [chamada de turma], de conviver mais com a pessoa que viria a ser minha parceira e construir aquela percepção maior sobre o município em que eu iria atuar. (E10).

Outra situação-limite apontada quanto à organicidade do curso foi a falta de transparência na formação das duplas, que estariam sendo constituídas sem um olhar cuidadoso para as singularidades dos sujeitos que as compõem. Como resultado, estar-se-ia enfrentando, nos territórios, uma dupla em conflito entre si quando deveria atuar da maneira mais harmônica possível com os/as educandos/as.

Esses encontros não dizem muito sobre o educador [...]. Têm que procurar uma forma de se avaliar a dupla, as personalidades [...]. Se as pessoas pudessem ficar a par de quem tá colocando para trabalhar junto [...], mas continua o mesmo problema, ninguém quer falar! [...]. Tolerar é uma coisa, conviver é outra. As pessoas vão estar trabalhando juntas. Se elas pensam o contrário, como é que chegam nesse ideal? É difícil! (E11).

Todavia, a fala acima demonstra certo desconhecimento de que, nesta edição, alguns/ as educadores/as do curso já estavam selecionados/as pela edição anterior, enquanto os/as que compunham o processo seletivo inscreveram-se para as vagas de cada município definidas pelo edital. Dessa maneira, questiona-se quanto ao conhecimento do conteúdo do edital, como um todo pelos/as educadores/as. Além disso, ressalta-se a complexidade do trabalho da coordenação de olhar para as singularidades tanto dos municípios quanto dos sujeitos, assegurando as normas institucionais.

[...] sofria alguma forma de preconceito em relação à religiosidade [...]. Quando eu via que a pessoa tinha um discurso [...] afiado em cima dos evangélicos, criava uma oportunidade de dialogar [...]. Existem várias pessoas em várias religiões e, dentro dos contextos, pessoas que são diferentes [...]. (E14).

A aceitação das diferenças é um dos princípios pedagógicos da educação popular ${ }^{13}$ que se articula diretamente à participação democrática, reconhecendo, na diversidade, a possibilidade de construção de uma sociedade equânime ${ }^{23}$. Assim sendo, a fala sobre o preconceito religioso chama atenção. Porém, reconhece-se que o curso possibilitou trazer para a roda as contradições da sociedade capitalista. Nesse âmbito, os princípios da educação popular, no caso, o diálogo, foram acessados como atos-limites para sua superação. Apesar disso, mostra-se relevante o questionamento sobre uma possível padronização envolvendo a educação popular. A religião em questão vem crescendo no País, portanto, não é usualmente demonstrada como alvo de preconceitos, ou de 'minorias'. Então, perguntam-se: estar-se-iam, enquanto educadores/as, estigmatizando pessoas que comungam manifestações culturais ou religiosas que se incluem na ordem hegemônica?

Uma defasagem [...] é inevitável estar numa situação de autoridade quando se é professor. Somos responsáveis pelo processo. A formação tinha que ser um preparo para o território e o que a gente viveu de mais turbulento foi não saber como lidar com a autoridade de maneira harmoniosa [...]. (E13).

O/A educador/a aponta que trabalhar a autoridade do/a educador/a, sem que isso 
se materialize como autoritarismo, foi uma lacuna do curso. A condução do/a educador/a em uma proposta pedagógica libertária leva à complexa tarefa de mediar a tensão contínua entre autoridade e liberdade ${ }^{13}$. O contexto histórico e social no qual os sujeitos foram construídos imprimiu a ideia de harmonizar os conflitos com completa passividade. No entanto, uma educação que visa ao ser-mais do humano põe, em relação, liberdade e autoridade, em um jogo ativo entre bom senso, amorosidade e coragem, explicitando conflitos e contradições na busca do diálogo ${ }^{26}$; dando-se, assim, a harmonização entre educador/a e educando/a.

\section{'Quando o vento sopra e apaga as velas, tem que ajustar': o processo de ação-reflexão-ação}

[...] se fortalecer com os companheiros, com o que estavam fazendo nos territórios, mesclar com o que você fazia no seu. Somos diferentes, mas a gente tinha pilares que sustentavam nossa ação [...]. Juntar os educadores todo mês [...] não se encontrar só no começo e no final. É um processo, vai dialogando, vai sendo trilhado, não se visa só o produto. É nesse percurso que a gente vai aprendendo [...]. (E12).

De forma autônoma, a coordenação do EdPopSUS no Ceará decidiu dar continuidade ao processo formativo dos/as educadores/as após o início dos encontros nos municípios, configurando-se em momentos formativos periódicos. A ação visou acompanhar o processo nos municípios, construir o compartilhamento dos saberes para a superação dos desafios e a sistematização das experiências.

[...] você já foi pra lá, viu como é, sentiu dificuldades, outros educadores também, [...] a dinâmica que um trabalhou, saiu da sala, chamou convidados, [...]. A coordenação foi conduzir o processo para que a gente aprendesse uns com os outros. Foram trocas que enriqueceram as possibilidades da gente. (E4).
Os/As educadores/as ressaltaram o papel da coordenação, não só pela iniciativa, mas também pela condução que visava mais a troca - entre eles, dos saberes produzidos nos territórios - do que apontar o que deveria ou não ser feito. Novos caminhos surgiram.

A formação revelou que se comprometer com a educação permanente dos/as educadores/as é comprometer-se com seus territórios de atuação. Fato que corrobora a necessidade de transformar a presença no contexto em estar com ele ${ }^{13}$. Dessa forma, propiciam-se relações mais distanciadas da pura objetividade, bem como da frieza que usualmente perpassam as relações entre educadores/as e educandos/as.

Quando o vento sopra e está só apagando as velas, tem que ajustar, trazer o que foi construído da formação [dos territórios] e, em contato com os educadores e com a coordenação, encontrar jeitos novos de caminhar, identificando as dificuldades e trazer um retorno para o território. [...] não apenas a formação antes de iniciar os encontros [...] para que a gente pudesse tá atento ao que acontecia nos territórios [...]. (E23).

A continuidade da formação também propiciou a vivência de situações-limites. "[...] estar presente em muitos locais ao mesmo tempo fragilizou o acompanhamento [...]" (E18). Tal fragilidade pode ter se dado por diversos fatores: desde a amplitude territorial do curso, que abrangeu 12 municípios em diferentes regiões do estado, até a equipe reduzida de coordenação, passando pela forma autônoma de condução dessa etapa, visto que, a princípio, não haveria apoio financeiro para tal.

A dificuldade de convivência entre os sujeitos implicados nesses momentos também foi mencionada:

[...] é um reflexo da convivência do ser humano quando a gente não se conhece, se não tiver uma escuta apurada e não propor um diálogo com amorosidade, termina que já cria certos enfrentamentos e reações [...]. (E5). 
A seleção reuniu companheiros/as de luta, mas também pessoas que não se conheciam.

[...] exigiu muito do trabalhar o tempo. Quantos municípios tinha ali para estar vivenciando as experiências? [...] teria prazos momentos e horários para estar cumprindo. Todos os momentos, a gente não teve educadores presentes, isso traz para o outro lado marginalizar nossas defesas [...]. (E8).

Movimentos que buscam imprimir uma participação maior da população nas sociedades, historicamente, sofrem ataques intensos pelo medo das elites à perda de seus privilégios. A necessidade de aperfeiçoar a organização, incluindo a dimensão burocrática, configuraria estratégia de legitimação das defesas dos movimentos, impactando positivamente no pouco tempo do qual dispunha a educação permanente dos/as educadores/as. Foi apontada, ainda, como situação-limite, pelo/a educador/a, a falta de compromisso que estaria se revelando na não presença de todos/as os/as educadores/as em tais momentos. Aponta-se, mais uma vez, para o âmbito relacional; mas não apenas isso. Para que haja compromisso, é imprescindível que, além da presença, ou seja, do estar no curso, esteja-se com o coletivo que $o$ abrange.

\section{Considerações finais}

A dinâmica neoliberal dificulta o encontro dos/as educadores/as consigo mesmos/as e a vivência dos saberes adquiridos com os movimentos sociais nos espaços institucionais. Em contraponto, desvaloriza as práticas solidárias excluindo a dimensão da coletividade. Os desafios postos nos encontros iniciais do processo formativo e seletivo de 40 horas do EdPopSUS teriam propiciado superações dessas e de outras situações-limites, como a relação entre educadores/as e a inclusão das singularidades, elucidando caminhos para sua atuação nesse contexto. Alimentados/as pelo desejo do encontro com companheiros/as de luta ou de novos aprendizados que incluíam suas subjetividades, ativou-se o esperançar.

O sistema educativo que reafirma valores dominantes na sociedade brasileira, como individualismo, diferenciação e distinção, pressupõe, ainda, que o/a educador(a)/trabalhador(a) tenham um saber pronto. A formação, perpassada pelos princípios da educação popular, pôde demonstrar a importância do reconhecimento de si como ser inacabado diante de tal imposição. A contextualização possibilitou reflexão acerca das fissuras existentes, na conjuntura atual, para uma prática libertária. Além disso, a inclusão do saber-de-experiência-feito contribuiu para a superação da passividade, fortalecendo o protagonismo dos/as educandos/as e delineando um/a educador/a desapegado/a dos saberes já construídos em nome da construção coletiva de saberes que se mostrem mais bem contextualizados.

Ao invés de pautar-se apenas na racionalização desses princípios, a formação pautou-se na vivência deles/as, complementando-a com propostas do âmbito mais racional, a exemplo da sistematização de experiências. A proximidade entre o dito e o praticado por parte da coordenação possibilitou a condução de forma coletiva em meio à complexidade que envolve uma seleção. Esta, todavia, configurou-se situação-limite, visto que o teor competitivo implicaria uma contradição com os objetivos da educação popular. A não presença de todos/as os/as educadores/as no curso apontou para a dificuldade da convivência e da construção coletiva.

A composição das duplas de educadores/ as estaria se dando de forma pouco clara; ao mesmo tempo, a falta de conhecimento sobre o edital contribuiria para tal falta de esclarecimento. Como consequência, ter-se-iam conflitos e desarmonia na condução em dupla, visto que teria sido formada sem priorizar uma harmonia entre as singularidades desses sujeitos. As possíveis saídas perpassariam pelo olhar sobre tais singularidades, sem deixar de lado os contextos dos municípios e das normas que envolviam a institucionalidade do curso. 
O preconceito religioso foi apontado como situação-limite na formação, o que pode estar revelando a falta de atualização da educação popular em sua relação com padrões de subjetividades hegemônicas. Contudo, o diálogo configurou-se ato-limite para essa situação. Trabalhar a autoridade do/a educador/a foi apontado como uma lacuna da formação.

Dar continuidade ao processo formativo dos/as educadores/as e a condução de tais momentos por iniciativa autônoma da coordenação estadual possibilitou um melhor acompanhamento do processo nos municípios, efetivando a educação permanente dos/ as educadores/as como compromisso com os territórios, a construção compartilhada de saberes na superação de desafios e a sistematização dessas experiências.

Dentre situações-limites do processo de continuidade, foram ressaltadas as dificuldades na convivência, o número reduzido da equipe para o acompanhamento nos municípios, o pouco tempo dos encontros e a não presença de todos/as os/as educadores/as. Para sua superação, seria necessário o aperfeiçoamento da organização, incluindo a dimensão burocrática, como estratégia de legitimação das lutas e a reafirmação do compromisso não apenas com o curso, mas com o coletivo da educação popular em saúde.

\section{Colaboradores}

Dantas MA (0000-0001-5454-5776)*, Silva MRF (0000-0002-6086-6901)*, Castro Júnior AR (0000-0002-3681-3607)* e Oliveira LC (0000-0001-8265-7476)* contribuíram igualmente na elaboração do manuscrito.

\section{Referências}

1. Queiroz DM, Silva MRF, Oliveira LC. Educação Permanente com Agentes Comunitários de Saúde: potencialidades de uma formação norteada pelo referencial da Educação Popular e Saúde. Interface. 2014; 18(2):1199-1210.

2. Brasil. Secretaria-Geral da Presidência da República. Marco de Referência da Educação Popular para as Políticas Públicas [internet]. Brasília, DF: Secretaria Geral da Presidência da República; 2014. [acesso em 2019 jan 21]. Disponível em: http://confinteabrasilmais6.mec.gov.br/images/documentos/marco_de_ referencia_da_educacao_popular.pdf.

3 Prodanov CC, Freitas EC. Metodologia do trabalho
científico: métodos e técnicas da pesquisa e do traba-
lho acadêmico. 2. ed. Novo Hamburgo: Feevale; 2013.

4. Yin RK. Estudo de caso: planejamento e métodos. 3. ed. Porto Alegre: Bookman; 2005.
${ }^{\star}$ Orcid (Open Researcher and Contributor ID). 
5. Minayo MCS. O desafio do conhecimento: pesquisa qualitativa em saúde. 9. ed. São Paulo: Hucitec; 2006.

6. Cavalcante RB, Calixto P, Pinheiro MMK. Análise de conteúdo: considerações gerais, relações com a pergunta de pesquisa, possibilidades e limitações do método. Inf. \& Soc.: Est. [internet]. 2014 [acesso em 27 jan 2019]; 24(1):13-18. Disponível em: http:// periodicos.ufpb.br/index.php/ies/article/viewFile/10000/10871.

7. Souza MAR, Wall ML, Thuler ACMC, et al. O uso do software IRAMUTEQ na análise de dados em pesquisas qualitativas. Rev. Esc. Enferm. USP. 2018; 52:1-7.

8. Guatarri F, Rolnik S. Micropolítica: cartografias do desejo. 4. ed. Petrópolis: Vozes; 1996.

9. Ceccim BR. Educação Permanente em Saúde: desafio ambicioso e necessário. Interface. 2004/2005; 9(16):161-177.

10. Alves R. Conversas com quem gosta de ensinar. Guarulhos: Cortez; 1980.

11 Freire P. Extensão ou Comunicação? 17. ed. São Paulo: Paz e Terra; 2015.

12. Freire P. Ação Cultural para a Liberdade e outros escritos. 14. ed. Rio de Janeiro: Paz e Terra; 2011.

13. Freire P. Pedagogia da Autonomia. 43. ed. São Paulo: Paz e Terra; 2011.

14. Kinker FS. Encontro terapêutico ou processo-metamorfose: desafio dos serviços territoriais e comunitários. Saúde debate. 2012; 36(95):695-701.

15. Pinafo E, Nunes EFPA, González AD, et al. Relações entre concepções e práticas de educação em saúde na visão de uma equipe de saúde da família. Trab. Educ. Saúde. 2011; 9(2):201-221.

16. Freire P. Educação como prática da liberdade. 40. ed. São Paulo: Paz e Terra; 2017.
17. Bonetti PO, Pedrosa JIS, Siqueira TCA. Educação popular em saúde como política do Sistema Único de Saúde. Revista APS. 2011; 4(14):397-407.

18. Morosini MVGC, Fonseca AF, Lima LD. Política Nacional de Atenção Básica 2017: retrocessos e riscos para o Sistema Único de Saúde. Saúde debate. 2018; 42(116):11-24.

19. Paim JS. Sistema Único de Saúde (SUS) aos 30 anos. Ciênc. Saúde Colet. 2018; 23(6):1723-1728.

20. Bello E, Bercovici G, Lima MMB. O fim das ilusões constitucionais de 1988? Rev. Direito e Práx. 2018; 20(10):1-43.

21. Miranda AS. A Reforma Sanitária encurralada? Apontamentos contextuais. Saúde debate. 2017; 41(113):385400.

22. Santos M, Silveira ML. O Brasil: território e sociedade no início do séc. XXI. 9. ed. Rio de Janeiro: Record; 2006.

23. Brasil. Ministério da Saúde. Portaria no 2.761, de 19 de novembro de 2013. Institui a Política Nacional de Educação Popular em Saúde no âmbito do Sistema Único de Saúde - PNEP-SUS. Diário oficial da União. 3 Jan 2013.

24. Freire P. Pedagogia do oprimido. 50. ed. São Paulo: Paz e Terra; 2011.

25. Beauvoir S. O pensamento da direita hoje. 2. ed. São Paulo: Paz e Terra; 1972.

26. Freire P. Professora, sim. Tia, não. 27. ed. São Paulo: Paz e Terra; 2017.

Recebido em 01/07/2019

Aprovado em 08/04/2020

Conflito de interesses: inexistente

Suporte financeiro: Coordenação de Aperfeiçoamento de Pessoal de Nível Superior (Capes) 